\title{
PROPAGAÇÃo de PTERIDÓFITAS IN VITRO E IN VIVO ATRAVÉS DE ESPOROS(')
}

\author{
FLÁVIA PROSPERO BOREUI $(2,3)$, CARLOS EDUARDO FERREIPA \\ DE CASTRO( (3), LUIZ ANTONIO FERRAZ MATTHES( $($ ). \\ ANTONIO FEANANDO CAETANO TOMBOLATO( $(3)$ - VOLETA NAGAI(4)
}

\section{RESUMO}

Sujeitas ao processo de extinção, em decorrencia do extrativismo, as samambaias arboreas Dicksonia sellowiana (Presl.) Hook e Cyathea schanschin Mart, das quais se obtém o xaxim, săo espécies ainda pouco estudadas quanto à propagaçăo. Com o objetivo de desenvolver um método adequado à propagaçăo destas espécies, através de esporos, realizaram-se experimentos in vito e in vivo. Para a desinfeccăo dos esporos, utilizaram-se soluçð̌es de hipoclorito de cálcio, em diferentes concentraçðes, ou de sódio, comparando-se sua eficiencia. Para o cultivo in vitto, empregaram-se os meios nutritivos de Murashige e Skoog modificado e de Jones e a soluçăo de Knop modificada. Na cultura in vivo utilizaram-se xaxim, esfagno, terriço ou tjolo fragmentado. Como condiçőes de cultivo, manteve-se a temperatura a $25 \pm 1^{\circ} \mathrm{C}$ o fotoperíodo de 16 horas. Apesar da elevada contaminaçăo durante o processo de germinaçăo in vitro e in vivo, a desinfecçăo com hipoclorito de cálcio a $2 \%$ foi mais eficiente. Os esporos germinaram em 4 a 8 semanas e os prótalos formaram-se apos 30 a 40 dias. Obteve-se maior percentagem de germinaçăo e formaçăo de prótalos com os meios de Jones e Knop, bem como xaxim e esfagno, e a germinaçăo de esporos ocorreu mais rapidamente na ausencia de esporangios.

Termos de indexação: pteridbfitas, cultura in vivo e in vitro; esporos, propagaçåo.

(1) Trabaitho parciaimente financiado pela FAPESP. Recebido para publicaçăo em 25 de malo e aceito em 17 de setembro de 1990.

(2) Estagiária bolsista da FAPESP.

(3) Seçăo de Foricultura e Plantas Ornamentais, Instituto Agronomico de Campinas (IAC), Caixa Postal 28, 13001 Campinas, SP.

(4) Seçăo de Trenica Experimental e Cálculo (AC). 


\section{ABSTRACT \\ FERN PROPAGATION IN VITRO AND IN VIVO FROMSPORES}

The objective of this experiment was to study the fern propagation from spores of Cyathea schanschin Mart and Dicksonia sellowiana (Presl.) Hook. The spores were decontaminated in calcium or sodium hypochlorite solutions. The in vito experiments were performed with the media: MS modified, Jones or Knop's solution modified. Tree-fern fibre, sphagnum moss, loam soil or brick peaces were, used for the in vivo experiments. The temperature wos mantained at $25 \pm 1^{\circ} \mathrm{C}$ and 16 hours of photoperiod for both treatments in vivo and in vitro culturesl. Besides the high percentage of contamination during the germination process, in vitro and in vivo, the best results were obtained with decontamination made in a $2 \%$ sodium hypochlorite solution. The spores germination occurred after a period of 4 to 8 weeks and the prothalli were formed 30 to $\mathbf{4 0}$ days latter. There was a high percentage of germination and prothalli formation in Jones and Knop media, and tee-tern fibre and sphagnum moss substrates.

Index terms: Ptoridophytes, in vivo and in vitro cultures; spores; propagation.

\section{INTRODUÇÃO}

O cultivo de flores $\theta$ plantas ornamentais é uma atividade agricola caracterizada pelo aproveitamento de pequenas áreas. Entre as plantas ornamentais, as pteridófitas, com destaque às samambaias e avencas, săo muito utlllzadas comercialmente.

Conjuntamente à questão comercial, é de considerar o aspecto relaciónado à preservação ambiental ligado à exploraçăo intensiva $\theta$ indiscriminada das pteridofitas como um todo.

A constante e crescente devastação de várlas espécies vegetais ocorre, principalmente, através do extrativismo, e sua devida reposição não é realizada, acelerando, assim, seu processo de extinçăo.

No Brasil, algumas samambaias arbóreas encontradas na serra do Mar são: Cyathea gardneri Hook, Cyathea schanschin Mart, Trichipteris atrovirens (Langsd. \& Fisch) Tryon, Nephelea sternbergil (Pohl.) Tryon, Alsophila corcovadensis (Raddi) C. Ch. e Dicksonia sellowiana (Prest.) Hook. Esta última espécle se encontra em processo de extinção, pois, por seu intermédio, ́́ que se obtém o xaxim verdadeiro, intensamente utilizado (isolado ou em mistura com outros componentes) como substrato para outras espécies ornamentais, como orquideas e bromélias. Atualmente, é realizada a extração do xaxim da espécie Cyathea schanschin Mart. em substituição à Dicksonia sellowiana (Presl.) Hook.

O défice, entre a retirada das plantas dos seus habltats e sua reposiçăo, pode ser amenizado, se forem dirigidos estudos com o intulto de produzitas em níveis quantitativos e qualitativos adequados ao suprimento da demanda. 
Um dos estudos pioneiros sobre a cultura in vitro com pteridófitas foi efetuado por HIRES (1940), mediante inoculação de esporos de Polypodium aureum J. Sm. em meio nutritivo sólido.

O meio de Murashige e Skoog (MS) foi comercialmente utilizado para pteridófitas, pela primeira vez, em 1976, com Nephrolepis exaltata (L.) Schott. Atualmente, muitos laboratórios utilizam o método definido para esta espécie na produção de outras samambaias.

KNAUSS (1976) cultivou in vitro esporos de Pteris ensiformis Burm., Adiantum tenerum Swartz, 'Pink Lady', Cyromium falcatum Presl., Davallia bullata Wall., Polystichum adiantiforme (Foerst) J. Sm. e Platycerium bifurcatum C. Chr. Os esporos foram inoculados em meio MS modificado, suplementado com sacarose, tiamina e ágar, mantendo-se um pH de 5,7 a 5,8 $\theta$ como condiçōes de cultivo, um fotoperíodo de 16 horas e uma temperatura de $27^{\circ} \mathrm{C}$. Verificou-se que, para as espécies de pteridófitas citadas, somente o estádio gametofítico foi produzido por cultura in vitro em MS modificado. A fragmentação das colônias de prótalo foi efetuada através de sua agitação em uma solução de sais (meio MS diluído à metade) por 5 segundos. Esta suspensão de tecido gametofítico foi, posteriormente, distribuida nos substratos. Após a transferência do material, foi produzido o estádio esporofítico.

LÊ (1983) implantou ensaio de cultura in vitro com esporos de Nephrolepis exaltata, em condiçōes de cultivo idênticas àquelas adotadas por KNAUSS (1976), alterando apenas a faixa de temperatura para 18 a $23 \pm 1^{b} \mathrm{C}$. Houve referências à necessidade de açúcar na composição do meio para que as colônias de prótalo se constitulssem, além da necessidade de transferência dos prótalos a um meio fresco da mesma composição, para que proliferassem rapidamente. O processo de fragmentação das colónias de prótalo realizou-se através da agitação delas em uma solução nutritiva de MS diluída a 1/4, com posterior distribuição nos substratos. Tal processo induziu o desenvolvimento de esporófitos.

FERREIRA NETO (1983) efetuou a inoculação te esporos de Cyathea delgadii Sternb. em solução líquida de Knop com as modificaçōes introduzidas por DYER (1979), mantendo os frascos, com os esporos inoculados, em luz fluorescente branca e à temperatura constante de $25^{\circ} \mathrm{C}$. O autor, realizando testes preliminares com diferentes períodos de pré-embeblção dos esporos no escuro e posterior manutenção em soluçāo de Knop em luz fluorescente branca por tempo definido, verificou que os tratamentos de pré-embebição no escuro por 48 ou 72 horas foram os mais efetivos. Verificou, também, que em nenhum caso os esporos germinaram em escuro constante, enquanto os que permaneceram sob condiçōes de plena luminosidade apresentaram os maiores índices, superando até os tratamentos de pré-embebição.

JONES (1987) referiu-se à técnica de inoculaçäo de esporos em meio sólido com pH ajustado para 6,0-6,5 ou 7,0-7,5, recomendando a supressão de açúcares do meio, visto que favorecem o surgimento e o desenvolvimento de fungos e bactérias. Essa recomendação contraria LÊ (1983). Para a inoculação de esporos in vivo, foram utilizados substratos como o esfagno, o xaxim, a areia grossa e o solo propriamente dito, isoladamente ou em mistura. Adicionaimente, 
- autor informa que a germinaçāo de algumas espécies de pteridófitas ocorre na presença de fungos micorrizicos, recomendando a desinfecçảo dos esporos em solução de hipoclorito de cálcio ou de sćdio ( $10 \mathrm{~g} / 140 \mathrm{ml}$ de água).

Após a formação dos prótalos, POOLE \& CONOVER (1973, 1978), FUJINO \& REID (1983), GILLIAM et al. (1983) e JONES (1987) informaram sobre a necessidade de proceder-se a suplementaçōes nutricionais com fertilizantes líquidos.

Na prática, tem-se observado que viveiristas efetuam a semeação de esporos de várias pteridófitas em fragmentos de tijolos com relativo éxito à propagação: estudos mais aprofundados são requeridos para avaliar sua eficiência.

Com o objetivo de desenvolver um método adequado à propagaçāo de Cyathea schanschin e Dicksonia sellowiana, através de esporos, realizaram-se experimentos in vitro $\theta$ in vivo, testando-se os diversos processos preconizados.

\section{MATERIAL E MÉTODOS}

Como material vegetal, foram utilizados esporos de Dicksoniasellowiana (Presi.) Hook, Cyathea schanschin Mart e Alsophila sp. coletados no Instituto de Botânica, Săo Paulo.

O estudo foi desenvolvido através de doze tratamentos com quatro repetiçőes, diferenciados pelas suas condições de cultivo, conforme o esquema abaixo:

In vivo:

$T 1$ = conjunto esporângios e esporos (E) em esfagno;

T2 = esporos (e) em estagno;

$\mathrm{T} 3=(E)$ em xaxim;

$T 4=(e)$ em xaxim;

T5 = (E) em terriço;

T6 $=(e)$ em terriço.

In vitro:

T7 = (E) em meio sólido de Jones;

T8 = (e) em meio sólido de Jones;

T9 = (E) em meio de Murashige e Skoog modificado;

T10 = (e) em meio de Murashige e Skoog modificado;

T11 = (E) em solução de Knop modificada por Dyer;

$\mathrm{T} 12=(e)$ em solução de Knop modificada por Dyer. 
Os meios de cultura utilizados tinham as seguintes composiçōes:

1) Meio solido de Jones (pH = 6,0-6,5): $\left(\mathrm{NH}_{4}\right)_{2} . \mathrm{SO}_{4} 1 \mathrm{~g}$ litro; $\mathrm{Ca}\left(\mathrm{NO}_{3}\right)_{2}$ $500 \mathrm{mg} /$ itro; $\mathrm{KCl} 250 \mathrm{mg} / \mathrm{itro} ; \mathrm{KH}_{2} \mathrm{PO}_{4} 250 \mathrm{mg} / \mathrm{itro} ; \mathrm{MgSO}_{4} .7 \mathrm{H}_{2} \mathrm{O} 250 \mathrm{mg} / \mathrm{litro}$; quelato de ferro 42mg/itro; $\mathrm{MnSO}_{4} 7,5 \mathrm{mg} / \mathrm{itro}$ e ágar $12,0 \mathrm{~g} / \mathrm{itro}$.

2) Meio nutritivo de MS modificado (pH $=5,7-5,8): \mathrm{NH}_{4} \mathrm{NO}_{3}$ $1.320 \mathrm{mg} /$ /itro; $\mathrm{KNO}_{3} 1.520 \mathrm{mg} / \mathrm{itro} ; \mathrm{CaCl}_{2} .2 \mathrm{H}_{2} \mathrm{O} 325 \mathrm{mg} / \mathrm{litro} ; \mathrm{MgSO}_{4} .7 \mathrm{H}_{2} \mathrm{O}$ 296mg/litro; $\mathrm{KH}_{2} \mathrm{PO}_{4} 136 \mathrm{mg} / \mathrm{litro} ; \mathrm{Na}_{2} \mathrm{EDTA} 37,3 \mathrm{mg} / \mathrm{litro} ; \mathrm{FeSO}_{4} .7 \mathrm{H}_{2} \mathrm{O}$ 27,8mg/litro; $\mathrm{H}_{3} \mathrm{BO}_{3} 6,2 \mathrm{mg} /$ /itro; $\mathrm{MnSO}_{4} .4 \mathrm{H}_{2} \mathrm{O}$ 22,3mg/litro; $\mathrm{ZnSO}_{4} .7 \mathrm{H}_{2} \mathrm{O}$ $8,6 \mathrm{mg} / \mathrm{litro} ; \mathrm{KI} 0,83 \mathrm{mg} / \mathrm{litro} ; \mathrm{Na}_{2} \mathrm{MoO}_{4} .2 \mathrm{H}_{2} \mathrm{O} \quad 0,25 \mathrm{mg} / \mathrm{litro} ; \mathrm{CoCl}_{2} .6 \mathrm{H}_{2} \mathrm{O}$ $0,025 \mathrm{mg} /$ itro; $\mathrm{CuSO}_{4} .5 \mathrm{H}_{2} \mathrm{O} 0,025 \mathrm{mg} / \mathrm{itro}$; tiamina $0,5 \mathrm{mg} / \mathrm{itro}$; sacarose $30 \mathrm{~g}$ /itro e ágar $7 \mathrm{~g}$ /itro.

3) Soluçăo de Knop modificada por Dyer (pH = 5,7): $\mathrm{MgSO}_{4} .7 \mathrm{H}_{2} \mathrm{O}$ $510 \mathrm{mg} /$ litro; $\mathrm{KNO}_{3} 120 \mathrm{mg} / \mathrm{itro} ; \mathrm{Ca}\left(\mathrm{NO}_{3}\right)_{2} .4 \mathrm{H}_{2} \mathrm{O} 144 \mathrm{mg} /$ itro; $\mathrm{KH}_{2} \mathrm{PO}_{4} 250 \mathrm{mg} / \mathrm{itro}$;

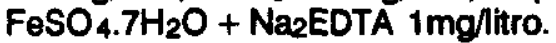

Os esporos foram obtidos de frondes férteis de pteridbfitas que apresentavam soros maduros; o conjunto de esporângios e esporos, pela separação em peneira de malha de 80 micros, e os esporos, pela separação subseqüente em peneira de malha de 120 micros.

Após a pesagem de várias parcelas de esporos, obteve-se uma média de $0,0013 \mathrm{~g}$ do material em cada inoculação.

A desinfecção de esporos ou conjunto de esporângios $\theta$ esporos fol efetuada com soluçóes de hipoctorito de cálcio $1 \%(1,53 \mathrm{~g}$ do produto comercial $/ 100 \mathrm{ml}$ de água); $2 \%$ (3,06g do produto comerclal $/ 100 \mathrm{ml}$ de água); $4 \%(6,12 \mathrm{~g}$ do produto comercial/100ml de água) ou $6 \%(9,18 \mathrm{~g}$ do produto comercial $/ 100 \mathrm{ml}$ de água), ou solução de hipociortito de sódio $20 \%$ (20ml do produto comercial Q-Boa/100ml de água).

Os esporos ou conjunto de esporângios e esporos foram agitados por 10 ou 20 minutos nas soluçōes de hipoclorito de cálcio, nas diferentes concentrações, ou de hipoclorito de sódio com a adiçāo de Tween 20.

Inocularam-se os esporos ou conjunto de esporángios e esporos nos meios (cultura in vitro) ou substratos (cultura in vivo), com o auxpiio de uma espátula metálica.

Para realização da cultura in vitro, utilizaram-se o meio sólido de JONES (1987), o meio nutritivo de Murashige \& Skoog (MS) modificado e a solução de Knop modificada por Dyer.

O meio sólido de MS modificado, ou de Jones, fol distribuido em placas de Petri ou em frascos de vidro. A soluçāo de Knop modificada por Dyer fol distribulda em tubos de ensalo com ou sem ponte de papel de filtro. Todo o material inoculado fol mantido em câmara clara a uma temperatura de aproximadamente $25 \pm 1^{\circ} \mathrm{C}$ e fotoperíodo de 16 horas. De acordo com as necessidades, efetuaram-se irrigaçőes com água bidestilada autoclavada (em condiçőes assépticas). 
Realizou-se a fragmentaçăo de algumas colônias de prótalo, obtidas através da cultura in vitro (meios sólidos de MS modificado ou Jones), de acordo com o método de KNAUSS (1976), ou seja, agitação daquelas em uma solução de sais (meio MS diluído à metade) por cinco segundos. Após esse processo, a suspensão de tecido gametofítico foi transferida para os substratos (xaxim ou esfagno). As colônias de prótalo e os prótalos isolados, obtidos em solução de Knop, foram diretamente distribuidas nos substratos, sem o uso do método de KNAUSS (1976).

A cultura in vivo foi realizada em vasos plásticos, preenchidos com $1 / 3$ da capacidade total, em sua porção inferior, com pequenos cacos de vaso, 1/3 de areia grossa lavada e 2/3 de substrato. Os substratos (xaxim peneirado, esfagno peneirado, terriço ou tijolo fragmentado) foram autoclavados por 20 minutos a $120^{\circ} \mathrm{C}$ ou mantidos em forno de microondas por 15 minutos. Após a inoculação, colocaram-se os vasos em bandejas cobertas por plásticos e mantidas em câmara clara com condiçöes idênticas às utilizadas para a cultura in vitro.

Efetuaram-se irrigações com água destilada, de acordo com as necessidades e, adicionalmente, fertilizações com soluçōes do produto comercial Hyponex (1 $\mathrm{g} /$ de água). Este fertilizante líquido fol distribuído nos recipientes, a partir da formaçăo dos prótalos.

A análise estatística foi realizada com base na distribuição binomial, considerando os cinco seguintes possiveis casos de resposta, nas quatro repeticões, e respectivos valores de proporção p e $q=1$ - $p$, e erro padrão $s(p)=$ $=\sqrt{\frac{p(1-p)}{n}}$

Casos
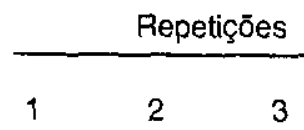

1

2

$\begin{array}{ll}3 & 4 \\ x & x \\ x & - \\ - & - \\ - & - \\ - & -\end{array}$

$-$

\begin{tabular}{ll}
\multicolumn{2}{c}{ Proporção } \\
\hline$p$ & $q$ \\
1,0 & 0 \\
0,75 & 0,25 \\
0,50 & 0,50 \\
0,25 & 0,75 \\
0 & 1,0
\end{tabular}

Erro padrão

$s(p)$

0

0,2164

0,25

0,2164

5

onde x se refere à presença e -, à auséncia da característica em estudo.

Com $68 \%$ de probabilidade, pode-se dizer que: (a) tratamentos com mesmo erro padrão e proporçōes diferentes diferem estatisticamente entre si; (b) tratamentos com erro padrăo igual a 0,25 e proporçöes $p=0,75$ e $p=0,25$ diferem entre si.

Devido aos resultados obtidos na primeira fase do trabalho, estudaram-se também os seguintes tratamentos, cujos resultados se encontram, respectivamente, nos quadros 4 e 5 . 
In vitro (Alsophila sp.)

T1 = esporos (e) em meio sólido de Jones (frascos de vidro);

$\mathrm{T} 2$ = (e) em meio sólido de Jones (placas de Petri);

T3 = (e) em MS modificado (frascos de vidro);

T4 = (e) em MS modificado (placas de Petri);

T5 = (e) em solução de Knop modificada por Dyer (tubos de ensaio).

In vitro (Cyathea schanschin)

$\mathrm{T} 1$ = (e) em solução de Knop modificada por Dyer (tubos de ensaio com ponte de papel de filtro);

T2 = (e) em solução de Knop modificada por Dyer (tubos de ensaio sem ponte de papel de filtro);

In vivo (Cyathea schanschin)

T3 = (e) em xaxim;

$\mathrm{T} 4$ = (e) em esfagno;

T5 = (e) em tijolo.

\section{RESULTADOS E DISCUSSÃO}

Constatou-se um elevado índice de contaminações por fungos e bactérias, independente da concentração do agente esterilizante empregado e do período de esterilizaçāo a que os esporos foram submetidos, o que prejudicou sensivelmente a germinaçăo. Pressupōe-se que a contaminaçäo manifestada esteja diretamente relacionada ao fato de as plantas matrizes serem mantidas em condições de campo, o que facilita o surgimento e desenvolvimento de grande número de microorganismos nas frondes. Ademais, a rugosidade da superfície dos esporângios e esporos também pode influenciar a penetração do agente esterilizante, a qual nem sempre ocorre em um nivel ótimo, dificultando, portanto, uma desinfecção mais eficiente.

Os resultados e discussão dos mesmos são apresentados por espécie.

1) Cyathea schanschin Mart.

No quadro 1, observa-se que, na desinfecção do material com hipoclorito de cálcio $1 \%$, os resultados foram insatisfatórios (contaminação $=100 \%$ ou $p=1$ ) para a cultura in vivo, situação atribuida a assepsia insuficiente a que foram submetidos os substratos. A contaminação do material (in vitro) fol malor em melo sólido de MS modificado do que em meio nutritivo de Jones, confirmando, 
portanto, a recomendação de JONES (1987): a presença de açúcar na composição do melo favorece o surgimento e o desenvolvimento de fungos e bactérias. O menor índice de contaminaçăo (in vitro) ocorreu em soluçảo de Knop: pressupő-se que esta apresente resultados mals satisfatórios quanto à contaminação do material porque não há necessidade de irrigações, evitando, assim, maior manuseio. Os esporos inoculados em placas de Petri e frascos de vidro (meios de cultura sólidos) necessitam ser irrigados, aumentando, portanto, a possibilidade de contaminaçōes.

Em relaçăo à germinaçāo, quando utilizado o meio solido de Jones, apesar da contaminaçăo, houve maior porcentagem de germinação de esporos na ausência de esporångios.

Não foi observado o desenvolvimento de esporófitos (in vitro): portanto, utiizou-se o método de KNAUSS (1976) para fragmentaçăo de colónias de prótalo (obtidas através de cultura in vitro) e com sua posterior transferéncia para os substratos (in vivo). O desenvolvimento de esporófitos fol observado quatro meses após o procedimento acima.

QUADRO 1. Proporção $(P)$ de contaminação, germinação e formação de prótalos nos diferentes tratamentos após a desinfecçăo de esporos (e) ou conjunto de esporångios e esporos (E) de Cyathea schanschin com soluçăo de hipoclorito de cálcio $1 \%$

Tratamentos

Hipoclorito de $\mathrm{Ca} 1 \%$

Germinaçăo
e Prótalos

In vivo
(E) esfagno
1,00
0,0
(e) esfagno
1,00
0,0
(E) xaxim
1,00
0,0
(e) xaxim
1,00
0,0
(E) terriço
1,00
0,0
(e) terriço
1,00
0,0

In vitro
(E) Jones
0,75
0,25
(e) Jones
0,75
0,75
(E) MS
0,75
0,0
(e) MS
1,00
0,0
(E) Knop
0,50
0,0
(e) Knop
0,50
0,25 

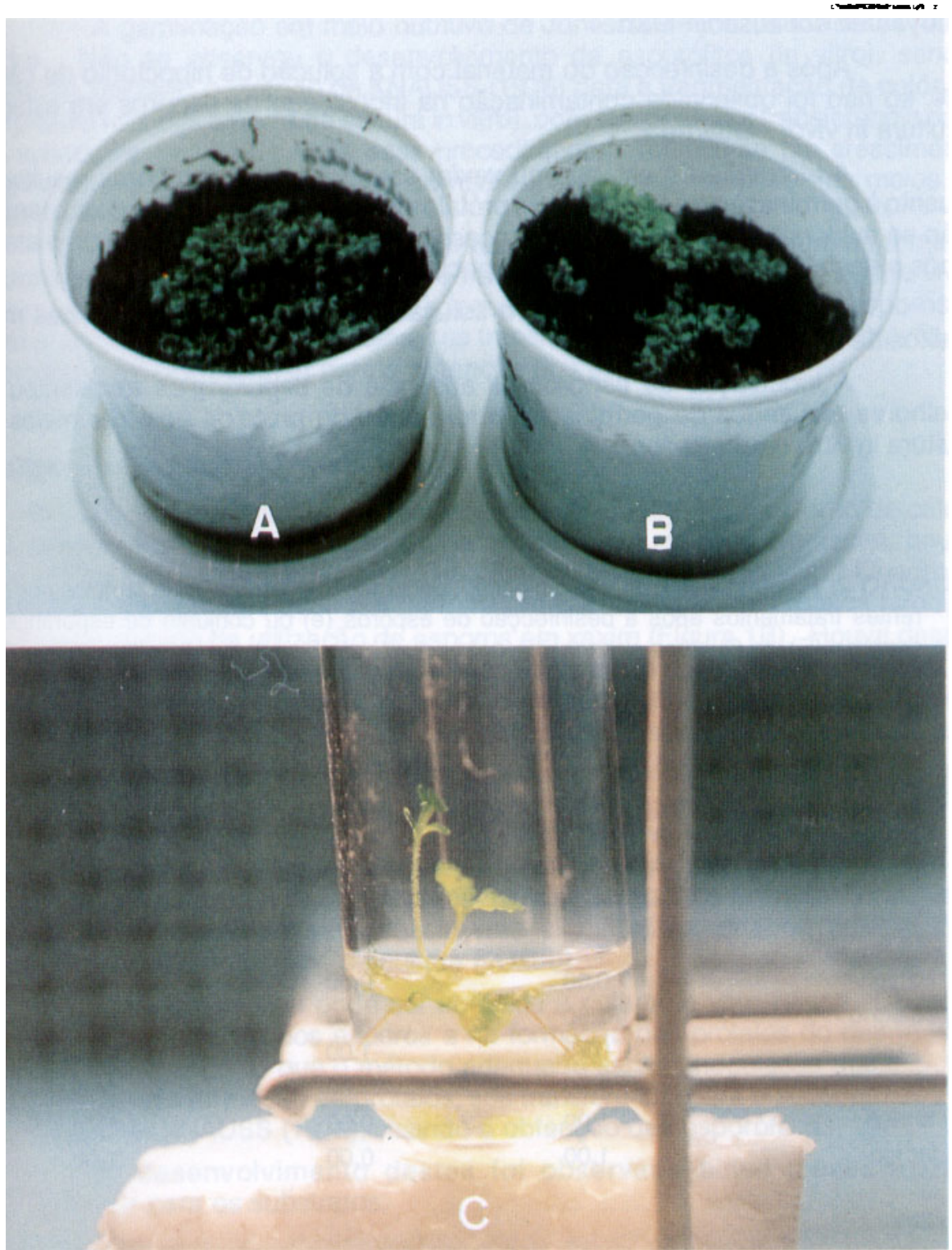

Figura 1. A: Prótalos de Cyathea schanschin e B: Prótalos de Dicksonia sellowiana, ambos obtidos pelo método de KNAUSS (1976), utilizando como substrato o xaxim; C: Formação de esporófitos de Cyathea schanschin em solução de Knop, sem ponte de papel de filtro. 
2) Cyathea schanschin Mart.

Após a desinfecção do material com a solução de hipoclorito de cálcio $2 \%$, só não foi observada contaminação na inoculação de esporos em esfagno (cultura in vivo) - Quadro 2.

A utilização de esfagno ou xaxim caracterizou os melhores resultados quanto à germinação e à formação de prótalos (Figura 1A), enquanto, com oterriço, não se evidenciou a ocorréncia do processo. Não houve germinação do material após a desinfecção com solução de hipoclorito de sర́dio $20 \%$.

Nos tratamentos in vitro, a soluçāo de Knop revelou os indices mais baixos de contaminação.

A inoculação de esporos na ausência de esporânglos apresentou os melhores resultados de germinação e formação de prótalos nos trés meios de cultura in vitro empregados.

QUADRO 2. Proporção (P) de contaminaçăo, germinaçăo e formaçăo de prótalos nos diferentes tratamentos após a desinfecção de esporos (e) ou conjunto de esporângios e esporos $(E)$ de Cyathea schanschin com soluçăo de hipociorito de cálcio $2 \%$ ou hipoclorito de sódio $20 \%$

Tratamentos

Hipoclorito de $\mathrm{Ca} 2 \%$

$\begin{array}{ccc}\text { Contaminação } & \begin{array}{c}\text { Germinaçăo } \\ \text { e Prótalos }\end{array} & \begin{array}{c}\text { Hipoclorito de } \mathrm{Na} 20 \% \\ \text { Contaminaçåo }\end{array}\end{array}$

In vivo

(E) esfagno

0,00

0,00

1,00

(e) esfagno

1,00

1,00

0,25

(E) xaxim

0,75

1,00

0,50

(e) xaxim

1,00

1,00

1,00

(E) terriço

1,00

0,00

1,00

(e) terriço

1,00

0,00

1,00

In vitro

(E) Jones

1,00

0,75

1,00

(e) Jones

0,75

1,00

1,00

(E) MS

0,75

0,00

1,00

(e) MS

1,00

1,00

1,00

(E) Knop

0,25

0,00

0,75

(e) Knop

0,25

1,00

1,00 
A germinação em meio nutritivo de Jones alcançou os melhores resultados. Não se observou o desenvolvimento de esporófitos (in vitro), sendo, portanto, utilizado o método de KNAUSS (1976) para a fragmentação de colônias de prótalo (obtidas através de cultura in vitro), com sua posterior transferência para os substratos (in vivo). Após esse procedimento, verificou-se um crescimento significativo dos mesmos quando comparados àqueles mantidos nos meios de cultura (in vitro).

A vantagem que pode ser atribuida à cultura in vitro refere-se à maior rapidez na germinação dos esporos e na formação dos prótalos do que in vivo. Assim, pressupōe-se que o método adequado seria a inoculação dos esporos in vitro e, após a formação de prótalos, sua transferência para o substrato através do método de KNAUSS (1976) para a obtenção dos esporófitos.

\section{3) Dicksonia sellowiana (Presl.) Hook}

Após a desinfecção do material com a solução de hipoclorito de cálcio $2 \%$, observou-se que, à exceção do tratamento com esporos em xaxim, houve uma contaminação de $100 \%, p=1$, nos demais tratamentos in vivo - Quadro 3 . Os melhores resultados quanto à germinação e à formaçāo de prótalos também ocorreram quando da utilização de esporos em xaxim (Figura 1B). Houve desenvolvimento de esporófitos seis meses apos a formaçăo dos prótalos em xaxim. A desinfecção com a solução de hipociorito de sódio $20 \%$ mostrou-se ineficiente (contaminação $=100 \%$ ), para a cultura tanto in vivo como in vitro.

A germinação e formaçăo de prótalos em melo MS modificado apresentou os melhores resultados quando utilizados esporos na auséncia de esporângios. Não houve formação de esporófitos (in vitro): assim, utilizou-se o método de KNAUSS (1976) para a fragmentação de colónias de prótalo (obtidas através de cultura in vitro), e posterior transferência para os substratos (in vivo). Após esse procedimento, notou-se seu crescimento significativo, quando comparados aqueles mantidos nos meios de cultura (in vitro).

A vantagem que pode ser atribuida à cultura in vitro refere-se à maior rapidez na germinaçáo dos esporos e na formação dos prótalos do que in vivo. Portanto, pressupõe-se que o método adequado seria a inoculação dos esporos in vitro e, após a formaçăo de prótalos, sua transferéncla para o substrato através do método de KNAUSS (1976), visando à obtenção dos esporófitos.

O desenvolvimento destes foi observado cinco meses após a transferéncia para os substratos.

\section{4) Alsophila sp.}

O quadro 4 mostra que a desinfecção dos esporos com a solução de hipoclorito de cálcio $2 \%$ levou a um menor índice de contaminação quando empregados frascos de vidro (Jones e MS modificado). Comparando-se as desinfecções com as soluções de hipoclorito de cálcio 2, 4 e 6\%, pode-se concluir que a primeira foi a mais eficiente quando empregados frascos de vidro e tubos de ensaio (solução de Knop.) Pressupõe-se que o aumento da concentração do 
agente desinfetante aumente a contaminação, pois provoca uma oxidação do material, favorecendo, assim, a açăo de microorganismos saprófitos.

QUADRO 3. Proporção (P) de contaminaçăo, germinaçăo e formaçăo de prótalos nos diferentes tratamentos após a desinfecçắo de esporos (e). ou conjunto de esporângios e esporos (E) de Dicksonia sellowiana com soluçăo de hipoclorito de cálcio $2 \%$ ou hipoclorito de sódio $20 \%$

Tratamentos

Hipoclorito de $\mathrm{Ca} 2 \%$

Contaminação $\quad \begin{gathered}\text { Germinaçáo } \\ \text { e Prótalos }\end{gathered}$

Hipoclorito de $\mathrm{Na} 20 \%$

Contaminaçăo

$\mathrm{p}$

In vivo

(E) esfagno

1,00

0,00

1,00

(e) estagno

1,00

0,00

1,00

(E) xaxim

1,00

0,00

1,00

(e) xaxim

0,50

0,75

1,00

(E) terriço

1,00

0,00

1,00

(e) terriço

1,00

0,00

1,00

In vitro

(E) Jones

0,50

1,00

1,00

(e) Jones

0,50

0,75

1,00

(E) MS

1,00

0,00

1,00

(e) MS

0,50

1,00

1,00

(E) Knop

0,50

0,75

1,00

(e) Knop

0,75

0,75

1,00

QUADRO 4. Proporção (P) de contaminaçăo nos diferentes tratamentos após a desinfecção de esporos (e) de Alsophila sp.com solução de hipoclorito de cálcio $2 \%, 4 \%$ ou $6 \%$

Tratamentos

Hipoclorito de cálcio

$2 \% \quad 6 \% \quad 6 \%$

\section{In vitro}

(e) Jones, frascos de vidro

0,50

0,75

1,05

(e) Jones, placas de Petri

1,00

1,00

1,00

(e) MS, frascos de vidro

0,50

1,00

1,00

(e) MS, placas de Petri

1,00

1,00

(e) Knop, tubos de ensaio

0,50

1,00

1,00 
A germinação dos esporos ocorreu a 30 dias da inoculação nos substratos. Os prótalos formaram-se 40 dias após a germinaçăo dos esporos e os esporófitos iniciaram o desenvolvimento 110 dias depois da formaçăo dos prótalos.

\section{5) Cyathea schanschin Mart.}

No quadro 5, observa-se que, após a desinfecção com hipoclorito de cálcio 2\%, à exceção da solução de Knop em tubos de ensaio com ponte de papel de filtro, foram obtidos resultados satisfatórios quanto à germinaçăo e à auséncia de contaminação. Na solução de Knop (cultura in vitro), o desenvolvimento de esporófitos ocorreu 40 dlas após a formação de prótalos (Figura 1C). Não existem referências quanto ao desenvolvimento de esporófitos (in vitro) na literatura consultada.

$O$ desenvolvimento de esporófitos (nos substratos de cultura in vivo) ocorreu 30 a 40 dias após a formação dos prótalos.

QUADRO 5. Proporçăo (P) de contaminação, germinação e formação de prótalos nos diferentes tratamentos após a desinfecção de esporos (e) de Cyathea schanschin com solução de hipociorito de cálcio $2 \%$

Tratamentos

Hipoclorito de $\mathrm{Ca} 2 \%$
Contaminação
Germinaçå̃o
e Prótalos

$p$

In vitro

$\begin{array}{rrr}\text { (e) Knop, tubos com ponte papel filtro } & 1,00 & 0,50 \\ \text { (e) Knop, tubos sem ponte papel filtro } & 0,00 & 1,00\end{array}$

In vivo
(e) xaxim
0,00
1,00
(e) esfagno
0,00
1,00
(e) tijolo
0,00
1,00

\section{CONCLUSŌES}

1. A germinação dos esporos ocorreu mais rapidamente na ausência de esporângios. 
2. Apesar do elevado índice de contaminação por fungos e bactérias durante o processo de germinação e desenvolvimento dos esporos, a desinfecção do material com a solução de hipoclorito de cálcio $2 \%$ mostrou-se mais eficiente em comparação às demais concentraçōes utilizadas.

3. O meio de cultura (in vitro) mais eficaz foi a solução de Knop sem ponte de papel de filtro.

4. A utilizaçăo de frascos de vidro em substituiçăo às placas de Petri para os meios sólidos (Jones e MS modíficado) mostrou-se satisfatória, pois reduziu a porcentagem de contaminaçăo.

5. O substrato (cultura in vivo) de maior eficlência foi o xaxim.

\section{AGRADECIMENTOS}

Os autores expressam os seus agradecimentos à Técnica de Laboratório da Seção de Floricultura e Plantas Omamentais, Sra. Ana Marla Molini Costa, cuja dedicação tornou possivel o atendimento de todas as etapas do presente trabalho.

\section{REFERENCIAS BIBLIOGRÁFICAS}

DYER, A.F. The culture of fern gametophytes for experimental investigation. In: _ , ed. The experimental biology of fems. London, Academic Press, 1979. p.253-305.

FERREIRA NETO, W.M. Efeito de luz e temperatura na germinação de esporos de Cyathea delgadil Sterb. Campinas, UNICAMP-Instituto de Biologia, 1983. 63p. Tese (Mestrado).

FUJINO, D.W. \& REID, M.S. Factors affecting the vase life of fronds of maidenhair fern. Scientia Horticulturae, Amsterdam, 21:181-188, 1983.

GILLIAM, C.H.; SHUMACK, R.L. \& EVANS, C.E. The effects of slow-release fertilizers on the growth and postproduction performance of Boston fern. HortScience, Alexandria, 18(4):442-444, 1983.

HIRES, C.S. Growing ferns from spores on sterile nutrient media. Journal of the New York Botanical Garden, New York, 41(490):257-266, 1940.

JONES, D.L. Encyclopaedia of ferns. Portland, Tímber Press, 1987. 433p.

KNAUSS, J.F. A partial tissue culture method for pathogen-free propagation of selected fems from spores. Proceedings of the Florida State Horticultural Society, Tallahassee, 89:363-365, 1976.

LE, C.L. Essai de multiplication de Nephrolepis exaltata par culture in vitro de tissu gamétophytique. Révue Suisse de Viticulture d'Arboriculture et d'Horticulture, Lausanne, 15(3):189-192, 1983. 
POOLE, R.T. \& CONOVER, C.A. Fertilization of Maidenhair fern, Adiantum raddianum K. Prest. HortScience, Alexandria, 13(2):176-177, 1978.

\& - Influence of dolomite and micronutrients on yield of leatherleaf fern. Proceedings of the Florida State Horticultural Society, Tallahassee, 86:372-374, 1973. 